\title{
Pregnant adolescents and nurses perspectives on accessibility and utilization of maternal and child health information in Ohangwena Region, Namibia
}

\author{
Joyce T. Shatilwe ( $\nabla$ jshatilwe@hotmail.com ) \\ University of KwaZulu-Natal \\ Khumbulani Hlongwana \\ University of KwaZulu-Natal \\ Tivani P. Mashamba-Thompson \\ University of Pretoria
}

\section{Research Article}

Keywords: accessibility, utilization, pregnancy, adolescent girls, maternal and child health information

Posted Date: October 28th, 2021

DOI: https://doi.org/10.21203/rs.3.rs-983815/v1

License: @ (1) This work is licensed under a Creative Commons Attribution 4.0 International License. Read Full License

Version of Record: A version of this preprint was published at BMC Pregnancy and Childbirth on April 5th, 2022. See the published version at https://doi.org/10.1186/s12884-022-04619-w. 


\section{Abstract Background}

The reasons for the inability of most pregnant adolescent girls to access and utilize maternal and child health information (MCHI) are not well-documented. This is despite the policy guidelines promoting the provision of this necessary information to pregnant adolescents in order to prepare them for delivery. This provision is one of the strategies envisaged to improve their attendance of ANC visits and their maternal and child health.

\section{Method}

Data for this study were collected using semi-structured in-depth interviews. These were conducted with 12 adolescent pregnant girls between the ages of 15 and 19 and eight nurses from four different health centres in the Ohangwena Region of Namibia. The study was conducted over the period of three months (December 2018 to March 2019). The data was grouped into clusters aided by NVivo computer software version 12. Data were organized and condensed in small units, prior to being coded, categorized, and finally grouped into main themes and sub-themes.

\section{Results}

Results revealed that long travel hours to reach the nearest clinics was amongst the leading challenges affecting accessibility and utilization of $\mathrm{MCH}$ for pregnant adolescent girls. This was exacerbated by poor support with transport fare, poor road infrastructure and non-availability of transport, and these factors were key barriers to accessibility and utilization of clinic services. Other barriers pertained to the family dynamics, such as disclosing the pregnancy to the family members prior to commencing antenatal care (ANC) visits and harsh treatment from family members after the disclosure.

\section{Conclusion}

The pregnant adolescent girls were concerned about their inability to access and utilize MCHI. The challenges identified made them susceptible to maternal complications, hence their inability to access relevant $\mathrm{MCHI}$ to prepare them for pregnancy. Health educational interventions should prioritize both the adolescent girls and their families for proper support, especially since the reactions of families on the pregnancy of their adolescent girls often negatively affect accessibility and utilization of maternal and child health services. Moreover, further research on adolescents' needs during pregnancy should be expanded to include their parents, in order to better inform policymakers.

\section{Background}

Approximately $99 \%$ of the world's maternal deaths occur in resource-limited settings [1]. Sub-Saharan Africa (SSA) alone accounts for two-thirds (66\%) of deaths [1], with a number of 2017/2018 publications reporting maternal deaths of 546 per 100000 live births in the region $[2,3]$. The lifetime risk of death for women in high-income countries (HICs) is as low as 1 in 2400, compared to 1 in 180 in lowincome countries (LICs) [1, 4]. In September 2000, world leaders signed the United Nations Millennium Development Declaration, which committed countries to reducing child mortality by two-thirds (MDG 4), reducing the maternal mortality ratio by three quarters (MDG 5A), and achieving universal access to reproductive health (MDG 5B) between 1990 and 2015 [5]. There are now new global commitments, such as the new Global Strategy for Women's, Children's and Adolescents' Health, ending the AIDS epidemic by 2030 and the sustainable development priorities. Namibia was a signatory country to the United Nations declaration [5]. While Namibia, as an uppermiddle-income country in SSA, has achieved the target for births to be attended to by skilled health providers, it fell short of meeting the target for the expired Millennium Development Goals (MDGs), which aimed to reduce maternal deaths to 56 for every 100000 live births by $2015[5]$.

In Namibia, adolescent pregnancy has increased from 15\% in 2006 to $18.6 \%$ in 2013 [6]. The number of adolescent pregnancies has remained high in the country, with some areas recording up to $38.9 \%$ adolescent pregnancies [5]. Adolescent girls are more likely to experience pregnancy-related complications due to obstructed labour and eclampsia, thereby increasing their risk of death [7]. Children born to adolescents are also more likely to have a low birth weight, ill-health, stunting, and other poor nutritional outcomes [1]. Most of 
these complications are preventable if pregnant women are prepared and they timeously access and utilize necessary MCHI for childbirth [4, 8]. Information and education are basic sexual and reproductive health rights; hence, increasing access to information on reproductive rights gives people choices and a sense of entitlement to quality services [5]. The implementation of the above mentioned new global targets and goals is anticipated to improve the maternal healthcare of many women and children, especially in resourcelimited settings.

There are several challenges that hinder the achievements of global targets to improve maternal and child healthcare, and these include accessibility and utilization of $\mathrm{MCHI}[9,10]$. The literature has shown that continued poor and unequal access to skilled maternal and child healthcare services remains a major challenge, not only in Namibia, but in the majority of resource-limited settings [10-13]. The challenges further contribute to poor accessibility and utilization of $\mathrm{MCH}$, since adolescent girls mostly get information when they present at health facilities for maternal health services [8]. In most Low-Middle-Income countries, there are a number of challenges that hinder the access and utilization of this health information, and these include distance to the nearest health facilities, delay in decisionmaking, financial constraints, and the attitudes of health professionals [8, 14].

There are multiple potential explanatory factors for the under-utilization of maternal and child care services, such as young maternal age; religion; poor education; unskilled occupation; poverty; low caste; parity (higher birth order were less likely to access antenatal services); lack of autonomy; poor familial support; lack of access to transport; and the high cost of care, and when it is accessed, the poor quality [15-17]. While some studies have also highlighted a wide number of factors that influence the utilization of $\mathrm{MCHI}$ including education, distance to the nearest health facilities, lack of network coverage, family members, lack of involvement in community engagement activities, lack of youth-friendly initiatives, socio-economic and cultural factors, literacy levels, economic status, lack of health outreach programmes and language [18-20], the effect of information and access to it and how it influences maternal health remains unknown, especially in marginalized and rural communities.

Namibia is committed to reducing maternal mortality, and this is evidenced by the implementation of life-saving skills training of trainers, routine maternal death reviews, improved infrastructure, strengthened adolescent sexual and reproductive health and rights, and improved prevention of mother-to-child transmission (PMTCT) strategies [15]. However, these initiatives need to be supported by local data from appropriately designed studies.

We, therefore, explored the user-provider perspectives towards the accessibility and utilization of $\mathrm{MCHI}$ by pregnant adolescents in the Ohangwena Region in Namibia. The study was underpinned by the Theory of change, which asserts that change is a rigorous yet participatory process whereby groups and stakeholders in a planning process articulate their long-term goals and identify the conditions they believe have to unfold for those goals to be met [21]. These conditions are modeled as desired outcomes, arranged graphically in a causal framework. It covers the following elements: basic elements of needs (the initial problem being addressed), inputs (resources), outputs (intended activities) and outputs (desired changes for service users) [22].

The main aim of the study was to identify challenges faced by adolescent girls during pregnancy with respect to accessing and utilizing maternal and child health information. It is anticipated that the results of this study will be useful to the Government of the Republic of Namibia, the community, and non-governmental organizations in improving the accessibility and utilization of maternal and health information by adolescent girls, in order to improve maternal health outcomes among this population group.

\section{Methods}

\section{Research paradigm}

This study was guided by the interpretive paradigm due to its ability to explore the phenomenon from the perspectives of the service users (adolescent girls) and service providers (nurses) [23,24]. By applying an interpretive paradigm, the researchers had a chance to view the world through the lenses and experiences of those participating in the provision and use of $\mathrm{MCHI}$ in their region.

\section{Study design}

An exploratory qualitative design was applied to explore the experiences of service users and service providers pertaining to the accessibility and utilization of MCHI during pregnancy in the Ohangwena Region in Namibia.

\section{Study setting and study population}


The study was conducted in the Ohangwena Region, which is one of the 14 political regions in Namibia. It shares international boundaries with Angola to the north and regional boundaries with the Kavango region to the east, Omusati region to the west, and Oshana and Oshikoto regions to the south. It is the second-highest populated region in Namibia with a population of 274650 [25]. Ohangwena is a rural region and one of the most poverty-stricken areas in the country [26]. In 2017, Ohangwena was rated as one of the regions with the highest prevalence of teenage pregnancy [26]. The major diseases in the region are pneumonia, malaria, diarrhoea, and HIV/AIDS [26]. The total population of pregnant women between the target ages of 15 and 19 was 693 . The total number of registered nurses and enrolled nurses and midwives working at the selected health centres and clinics was 57.

\section{Sample size and sampling strategy}

The study participants included twelve (12) pregnant adolescents from different villages across Ohangwena Region and eight (8) Nurses from two different health professional categories (registered nurse and enrolled nurse and midwifery) who were working in health centres and clinics, Ongha Health Centre, Odibo Health Centre, Engela Clinic and Eenhana Clinic in Ohangwena Region.

A purposive sampling strategy was applied to identify 12 participants out of the 98 potential participants from four purposively selected sites. The identification of potential participants was based on their professional categories: one nurse dealing with antenatal consultations per professional category per site (enrolled Nurse and registered nurse), culminating in the selection of two nurses per site. Furthermore, these potential participants were considered information-rich, based on their inputs into the quantitative aspects of the study.

Only the adolescents who were pregnant at the time of the data collection, aged 15 to 19 years old, 1-40 gestational weeks pregnant and resident of the Ohangwena Region, were considered for inclusion in the study. Excluded in the study were women below the age of 15 or older than 19, not from the Ohangwena Region, and not pregnant at the time of data collection. For the selection of the nurses, the following inclusion and exclusion criteria were applied: Inclusion criteria: any year of age, working at ANC clinics, registered nurses or enrolled nurse and those from midwifery, male or female; Exclusion criteria: staff members who were not nurses, nurses who were not working at antenatal clinics, nurses who had worked less than one month at an antenatal clinic.

\section{Data collection}

This study was conducted over a three-month period (December 2018 to March 2019). The lead researcher, who had some training on qualitative research, conducted semi-structured in-depth interviews with pregnant adolescents who presented for ANC visits at the four sites and with eight nurses from four different health centres and clinics. An interview guide used to generate data covered the following areas: Reasons for late to start of antenatal care, mode of transport to the clinic, the distance to the nearest clinics, waiting time and challenges affecting access to $\mathrm{MCHI}$.

A maximum of four interviews per day were scheduled through telephonic appointments. Each interview lasted for about 30-40 minutes per participant and no follow-up interviews were conducted. The interviews were conducted in Oshiwambo, since the participants were more comfortable to talk in their own language. The interview venues were determined by the participants to ensure that they were less inconvenienced. A majority of participants preferred to be interviewed at the nearest clinics and some preferred to be interviewed at their place of residence and maternity shelters, as they were closer to their time of giving birth. The interviews for nurses were conducted either at their clinics or health centres. With the participants' permission, note-taking and digital audio-recordings were used to record the data. Code saturation was reached at 10 interviews, as data collection and analysis were conducted iteratively. However, the meaning saturation was reached after interviewing all twelve selected pregnant adolescent girls.

\section{Data management}

Two university students experienced in qualitative research were recruited to transcribe the audio materials verbatim. For quality-check purposes, the lead researcher listened to the audio materials while reading the transcriptions, in order to assure the quality of transcription prior to translating from Oshiwambo to English. Notably, the lead researcher (JS) is competent in both Oshiwambo and English. Furthermore, a Ph.D. graduate from the University of Namibia independently verified the quality of the transcriptions. Data were exported into NVivo computer software version 12 for analysis.

\section{Data analysis}


Content analysis techniques were applied to analyze the data, the following process of content analysis being followed: Data was condensed in small units, and then the coding process was conducted. The process of categorization of the data followed and, finally, thematic analysis was conducted by classifying the data into sub-themes and main themes. The lead researcher (JS) immersed herself in data through several readings of the transcripts in order to generate concepts. To support the findings, verbatim quotes were extracted from the transcripts.

Three main themes and six sub-themes were identified. The main themes were: accessibility and utilization of MCHI; challenges to service delivery; and inadequate services.

\section{Results}

The pregnant adolescent girls' ages ranged from 15 to19 years and the nurses' ages ranged from 26 to 55 years. All pregnant adolescent girls were from rural settings. The nurses' years of experience ranged from 1 to 30 years. The demographic information for the nurses and pregnant adolescents who participated is presented in Table 1, while Table 2 shows the main themes and sub-themes on which results were based.

Table 1

Demographic characteristics of participants who provided their perspectives towards accessibility and utilization of maternal and child health information by pregnant adolescents in the Ohangwena Region, Namibia, $(N=12 \& N=8)$.

\begin{tabular}{|c|c|c|c|c|c|c|c|c|c|}
\hline $\begin{array}{l}\text { Participants } \\
\text { code } \\
\text { (adolescent } \\
\text { girls) }(\mathrm{N}= \\
12)\end{array}$ & Age & $\begin{array}{l}\text { Distance } \\
\text { to the } \\
\text { nearest } \\
\text { health } \\
\text { facility }\end{array}$ & $\begin{array}{l}\text { Level of } \\
\text { education } \\
\text { (grade) }\end{array}$ & $\begin{array}{l}\text { Education } \\
\text { status }\end{array}$ & $\begin{array}{l}\text { Gestational } \\
\text { age } \\
\text { (months of } \\
\text { pregnancy) }\end{array}$ & $\begin{array}{l}\text { Participants } \\
\text { code } \\
\text { (nurses)(N } \\
=8)\end{array}$ & $\begin{array}{l}\text { Years of } \\
\text { experience } \\
\text { at ANC } \\
\text { clinic (in } \\
\text { months) }\end{array}$ & $\begin{array}{l}\text { Age } \\
\text { of } \\
\text { nurse }\end{array}$ & Position/Rank \\
\hline EngCl \#21 & 18 & $>5 \mathrm{~km}$ & Grade 10 & $\begin{array}{l}\text { Primary } \\
\text { education }\end{array}$ & 7 & En\#01 & $\begin{array}{l}60 \\
\text { months }\end{array}$ & 27 & $\begin{array}{l}\text { Enrolled } \\
\text { nurse/midwifery }\end{array}$ \\
\hline EngCl \#11 & 18 & $5 \mathrm{~km}$ & Grade 8 & $\begin{array}{l}\text { Primary } \\
\text { education }\end{array}$ & 9 & En\#02 & 1 month & 26 & $\begin{array}{l}\text { Enrolled } \\
\text { nurse/midwifery }\end{array}$ \\
\hline EngCl \#08 & 19 & $>5 \mathrm{~km}$ & Grade 10 & $\begin{array}{l}\text { Primary } \\
\text { education }\end{array}$ & 8 & En\#03 & $\begin{array}{l}13 \\
\text { months }\end{array}$ & 28 & $\begin{array}{l}\text { Enrolled } \\
\text { nurse/midwifery }\end{array}$ \\
\hline OngHC \#09 & 15 & $>5 \mathrm{~km}$ & Grade 9 & $\begin{array}{l}\text { Primary } \\
\text { education }\end{array}$ & 5 & En\#04 & $\begin{array}{l}36 \\
\text { months }\end{array}$ & 27 & $\begin{array}{l}\text { Enrolled } \\
\text { nurse/midwifery }\end{array}$ \\
\hline OngHC \#16 & 16 & $3 \mathrm{~km}$ & Grade 9 & $\begin{array}{l}\text { Primary } \\
\text { education }\end{array}$ & 6 & Reg\#01 & $\begin{array}{l}360 \\
\text { months }\end{array}$ & 55 & $\begin{array}{l}\text { Registered } \\
\text { nurse }\end{array}$ \\
\hline ODHC \#07 & 18 & $5 \mathrm{~km}$ & Grade 11 & $\begin{array}{l}\text { Primary } \\
\text { education }\end{array}$ & 7 & Reg\#02 & $\begin{array}{l}11 \\
\text { months }\end{array}$ & 26 & $\begin{array}{l}\text { Registered } \\
\text { nurse }\end{array}$ \\
\hline $\begin{array}{l}\text { EenhCL } \\
\# 17\end{array}$ & 18 & $>5 \mathrm{~km}$ & Grade 10 & $\begin{array}{l}\text { Secondary } \\
\text { education }\end{array}$ & 4 & Reg\#03 & $\begin{array}{l}36 \\
\text { months }\end{array}$ & 27 & $\begin{array}{l}\text { Registered } \\
\text { nurse }\end{array}$ \\
\hline EngCL \#23 & 19 & $>5 \mathrm{~km}$ & Grade 10 & $\begin{array}{l}\text { Primary } \\
\text { education }\end{array}$ & 8 & Reg\#04 & $\begin{array}{l}12 \\
\text { months }\end{array}$ & 29 & $\begin{array}{l}\text { Registered } \\
\text { nurse }\end{array}$ \\
\hline $\begin{array}{l}\text { EenhCL } \\
\# 04\end{array}$ & 17 & $>5 \mathrm{~km}$ & Grade 10 & $\begin{array}{l}\text { Primary } \\
\text { education }\end{array}$ & 7 & & & & \\
\hline ODHC \#19 & 18 & $2 \mathrm{~km}$ & Grade 9 & $\begin{array}{l}\text { Primary } \\
\text { education }\end{array}$ & 8 & & & & \\
\hline OngHC \#14 & 17 & $3 \mathrm{~km}$ & Grade 8 & $\begin{array}{l}\text { Primary } \\
\text { education }\end{array}$ & 6 & & & & \\
\hline $\begin{array}{l}\text { EenhCL } \\
\# 29\end{array}$ & 18 & $>5 \mathrm{~km}$ & Grade 10 & $\begin{array}{l}\text { Secondary } \\
\text { education }\end{array}$ & 5 & & & & \\
\hline
\end{tabular}


Table 2

Sub-themes and themes

\begin{tabular}{|ll|}
\hline Sub-themes & Themes \\
\hline Distance challenges to the nearest clinics & Accessibility and utilization of MCHI \\
\hline Poor road infrastructure and transport & Challenges to service delivery \\
\hline Insufficient financial incentives & \\
\hline Attitudes and behaviour & \\
\hline Family dynamics & Inadequate services \\
\hline Psychosocial challenges & \\
\hline Lack of availability of IEC materials and guidelines &
\end{tabular}

\section{Accessibility and utilization of $\mathrm{MCHI}$}

Our results revealed that the distance to the nearest clinics, lack of transport, or poor road infrastructure to the clinics were key deterrents to most pregnant adolescent girls' access to and utilization of $\mathrm{MCH}$. This evidence was corroborated by the data generated from the interviews with nurses.

\section{Distance challenges}

We found that the majority of pregnant adolescent girls were not accessing $\mathrm{MCHI}$, mainly due to long walking distances to the clinics and health centres for ANC visits. One of the pregnant adolescents who was interviewed stated as follows:

'It is very long! I really do not know how long it is, but the distance is very long, if you go at 8 am, you might reach at 11 am. I would go walking. I would just wake up early in the morning when the sun rises, I am already on my way. Yes, when the clinic opens, I am already there after walking for three hours.' 17-year-old, seven months pregnant adolescent girl.

'They are just far from the health centre and there are no nearby clinics that they can attend to, like Omhedi village, there is no clinic there and it is far from the health centre itself. The women coming from that village coming to attend ANC visits here is very far from the clinic.' One-month maternal care experience, enrolled nurse/midwifery.

\section{Lack of transportation and poor road infrastructure}

Limited transport was reported by both the pregnant adolescent girls and the nurses alike. Poor road infrastructure to the clinic contributed to transport challenges, resulting in pregnant adolescents walking long distances to the clinics. The scarcity of cars in their areas permeated throughout the different interviews.

'There are not many cars. If you get one, it's only those going to work, but that's it. The cars do not pass the road many times. There are times that I walk three hours to the clinic to attend ANC visits if I didn't get transport. I go back at 10 am, because I also wait for the cars at the shopping centre.' 16-years-old, six months pregnant adolescent girl.

'When the pregnant adolescent girls come to start ANC visits and we ask them why they are starting late, they always tell us that it is because of transport.' Three years of maternal care experience, registered nurse.

\section{Insufficient financial support}

Nurses and pregnant adolescent girls were in agreement in that insufficient financial support from parents and partners was a major challenge limiting pregnant adolescent girls' access to $\mathrm{MCHI}$ at the clinics and health centres.

'The transport might be available but the money is scarce. You do not know where to get money and sometimes the parents do not have jobs nor your partner. Very often you do not have an income and the person who is supposed to help you does not have one either.' 19year-old, eight months pregnant adolescent girl. 
'Sometimes they do not have money to come to the clinic, some are staying very far and there is no one to support them financially.' One month maternal care experience, enrolled nurse/midwifery.

\section{Challenges of service delivery}

Pregnant adolescents raised their concerns that they could not access the $\mathrm{MCHI}$ due to challenges related to the attitudes and behaviour of staff at the clinics and health centres. Unpleasant attitudes and behaviour were not only displayed by staff, but also by their fellow pregnant adolescent peers. These difficulties were further complicated by family dynamics and psychosocial challenges. Moreover, nurses were concerned about the undesirable attitudes of the pregnant adolescent girls towards the healthcare staff and vice versa.

\section{Undesirable healthcare provider attitudes}

Pregnant adolescent girls' concerns pertained to being shouted and scolded at by the nurses. Some nurses expressed their views regarding their colleagues' negative attitudes towards pregnant adolescent girls.

'I remember there was a time where I was experiencing lower abdominal pain. I consulted a nurse about it and she shouted at me, said 'I do not know' but in a harsh voice. I just did not know what she meant.' 17-year-old, six months pregnant adolescent girl.

'Some pregnant adolescent girls will tell you that they went to start with ANC visits and the nurses were talking to them in a shouting manner, meaning the nurses attended to them in a bad way, shouting at them made them feel not happy and uncomfortable.' One month maternal care experience, enrolled nurse/ midwifery.

\section{Undesirable pregnant adolescent girls' attitudes}

It was indicated that pregnant adolescent girls were also presenting undesirable behaviour and attitudes, either towards family members or nurses. Nurses raised their concerns that some adolescent girls were concealing their pregnancy and were reluctant to start ANC, for no apparent reason despite family members convincing them to do so.

'When I went after three months, I didn't really know what ANC was all about. They just used to insist that I go to the hospital. And I would deny and tell them that I was not pregnant. I was hiding the pregnancy.' 17-year-old, six months pregnant adolescent girl.

'On the other hand, adolescents have a high defence mechanism, when their parents try to talk to them they will be answering back and using vague language, to a point where the parents will give up and never mention anything regarding their pregnancy. They go through denial stages where they would not want parents to mention anything about them sleeping out. Insulting parents, these parents do come here with complaints of such, and when we take their blood pressure, it is high.' 30 years of maternal care experience, registered nurse.

\section{Family dynamics}

Participants raised numerous concerns relating to accessing and utilizing $\mathrm{MCHI}$, which mainly revolved around being afraid to go for ANC and to get maternal and child health-related information, given that they would have to first disclose their pregnancies to their parents before starting the ANC. Nurses also raised their concerns about parents making decisions as to when adolescent girls should start ANC and what to wear at the clinic. Furthermore, a number of nurses expressed their views about the harsh treatment pregnant adolescent girls were receiving from their parents and family members after disclosing their pregnancy. Some girls living in the school hostel started their ANC visits late because they did not inform their parents first, despite living in the proximity to the clinic.

'I was afraid to tell my people at home that I was going to the clinic because I was afraid to be scolded since I am too young to become pregnant.' 18-year-old, nine months pregnant adolescent girl.

'They tell us that they were apparently scared to disclose their pregnancy to their parents. They mostly just start with ANC when the parents are aware of the pregnancy, as the parents are the ones that encourage them to start with ANC. 11 months of maternal care experience, registered nurse.

\section{Psychosocial challenges}

Self-blame for becoming pregnant at a young age was one of the important findings of this study, and which also affected access to $\mathrm{MCHI}$. Adolescents generally face stigma from other girls in the community and at school when they fall pregnant. Nurses confirmed the 
pregnancy-related stigma pregnant adolescent girls face from community members. This category is classified under two subcategories.

'I just thought maybe they will beat me up since I became pregnant at a young age.' 17-year-old, six months pregnant adolescent girl.

The second stigma came from peers who would laugh and stare at pregnant adolescents as they pass by.

'About challenges, is just that there is always that one person that will laugh at you that you are pregnant. It can be your friends that will laugh at you, or tell you that they don't want to hang with you no [any] more since you are now pregnant, or they just laugh when you walk past them. That was what l experienced.' 17-year-old, six months pregnant adolescent girl.

'First of all, these children feel embarrassed. They feel embarrassed because sometimes the people from their house do not even know of the pregnancy.' Three years of maternal care experience, enrolled nurse/ midwifery.

\section{Inadequate services}

Lack of services was reported as one of the challenges faced by pregnant adolescent girls. Some lacked the requisite knowledge needed to start ANC visits. Some clinics and health centres lacked the necessary services and materials to provide MCHI to the pregnant adolescent girls, as illustrated in the three sub-themes below.

\section{The limited source of information for adolescent girls}

The study revealed that information related to maternal and child health is only being accessed from the health facilities. No information, education, and communication (IEC) materials are being distributed in the community, either from the clinics or health centres, since they are neither available nor supplied.

'No, I wasn't aware that I needed to go to the clinic when my periods stopped.' 18-year-old, nine months pregnant adolescent girl. 'What I think makes these girls start with ANC in the second trimester, most people just lack information on the best time to start with ANC. Most of them do not have the information on when to start with ANC. Most of the time when they start and we ask them why they are starting this late they tell us they just did not know when they were supposed to start. There is really just a lack of information among the people.' One month maternal care experience, enrolled nurse/ midwifery.

\section{Long waiting hours}

Long waiting hours due to long queues was an important challenge faced by pregnant adolescents, which deterred them from honouring their next appointments. Nurses also raised similar concerns about the long queues and long waiting hours, leading to pregnant adolescent girls getting bored and at times sneaking away before getting ANC services. Often, only one nurse would serve these pregnant girls. Some spent long hours in queues at the clinics and health centres awaiting to receive not only antenatal services but also $\mathrm{MCHI}$.

'It takes me round about four hours to finish when I go for ANC visits. The clinic opens at eight, and I am most of the time second or fourth in the queue because I almost arrive at six o'clock, and by twelve o'clock I am done.' 17-year-old, six months pregnant adolescent girl.

'Sometimes the queue is the challenge. Sometimes when the pregnant adolescent girls get here and look at the number of people queued up, they do not join the queue because they are afraid to stay until late, it discourages them too, and some who would like to wait they just end up waiting in the queue till dawn.' Three years of maternal care experience, registered nurse.

\section{Lack of availability of MCHI packages or policy guidelines}

Our study participants shared their concerns regarding the lack of policy or guidelines for maternal and child healthcare at the clinics. Nurses only summarized textbook information obtained from training institutions. It was further revealed that each clinic or health centre has its own way of getting information to the pregnant adolescent girls. There are no IEC materials on maternal and child healthrelated information available to the public. 
'We do not receive any leaflets at all, we use to have leaflets about three years back but these years [at this time] we do not have them at all.' Five years of maternal care experience, enrolled nurse/ midwifery.

\section{Discussion}

This study aimed to identify challenges facing adolescent girls in accessing and utilizing MCHI during pregnancy. This is consistent with the SDG 3, which emphasizes ensuring universal access to sexual and reproductive healthcare services, which includes family planning, IEC, and the integration of reproductive health into strategies and programmes [27]. This study conforms to the Global Strategy for Women's, Children's and Adolescents' Health (2016-2030). The main findings revealed that accessibility and utilization of $\mathrm{MCHI}$ were major challenges, with special reference to long distances to health facilities, necessitating pregnant adolescent girls to walk long hours to the nearest clinics. Another finding was lack of road infrastructure and unavailability of transport which exacerbated accessibility challenges. Insufficient financial support for transport fare further limited access to MCHI services. Family dynamics added to pregnant adolescents' barriers to access and use of information. Parental controls were also key determinants of whether or not pregnant adolescent girls accessed and utilized clinic-based health services. Moreover, pregnant adolescents' fear, guilt, and anticipated parental reaction made it difficult for them to disclose their pregnancies.

Our study results compare well with what is documented in the literature regarding the long travel distances endured by pregnant women to access maternal healthcare services, which, in turn, affect access and utilization of health information [3, 27-31] and lack of transport and poor road infrastructure increased the challenges. This is consistent with the results of a study conducted in Odisha in India, in so far as accessibility and utilization of $\mathrm{MCHI}$, are concerned [32-34]. Additional studies conducted in Nepal Chitwan district also point to the non-availability of transport and lack of road infrastructure as major challenges to pregnant adolescent girls' access and utilization of health information [29]. Consistent with findings from several other studies conducted in sub-Saharan Africa, lack of financial support from family members and partners also affected pregnant women's ability to access and utilize maternal health services [28-32,35]. Only a few of the adolescent pregnant girls were receiving financial support from their partners or from their parents, but the majority were struggling to reach the clinics and health centres. In addition, a systematic review conducted across subSaharan Africa revealed that the positive economic status of adolescent women is associated with the use of maternal healthcare services [34-38]. Studies conducted in America revealed similar findings that pregnant adolescents experience financial hardship during pregnancy $[39,40]$.

Furthermore, some studies have revealed that poor adolescents are more likely to disengage from social networks, making them less likely to be reached by programmes aimed at improving maternal health service utilization of adolescent mothers [35, 41, 42]. Even though some pregnant adolescent girls indicated the willingness to visit the clinics and health centres, they were unable to do so due to issues related to family dynamics which played a major role in their decision-making. Adolescent girls need to disclose their pregnancy status to their mothers since mothers are the main decision-makers and potential sources of support for them to seek and receive maternal health services. The findings from this study revealed that disclosure of pregnancy is mostly done at a later stage, for fear of harassment or harsh treatment after pregnancy disclosure. Our findings are consistent with studies that revealed that limited autonomous decision-making do limit adolescent girls' capacity to control their reproduction and utilize health care services [34, 36, 42]. Similar to this study, one conducted in a high-income country (Canada) revealed that adolescents have no autonomous decisions on their sexual reproductive health [43]. In summary, poor access and utilization of maternal health services by pregnant adolescent girls affected both low- and high-income countries.

\section{Strengths And Limitations}

The in-depth interviews conducted provided an opportunity for the researcher to collect rich information and to understand the meaning of the phenomena from the perspectives of the users and the providers of the $\mathrm{MCHI}$. To our knowledge, this was the first study to focus on the adolescents' and nurses' perspectives towards the accessibility and utilization of this information in the remote settings of Namibia. Including adolescents and nurses in the same study enabled us to compare and contrast different perspectives, so that a balanced understanding of their experiences could be established.

Rigorous inductive analysis and interpretation of the data were followed to enhance the credibility and dependability of the study findings. Credibility was also ensured by identifying and describing the participants accurately and including their value-added to the understanding of the phenomena. In addition, the appropriate method of data collection was selected for ensuring the credibility of the study. A purposive sampling strategy that was applied also increased the trustworthiness of the study. While the sample size was pre-

Page 9/13 
determined, conducting the data collection and analysis iteratively helped us assess the point at which data saturation was or was not reached. A detailed explanation of how data were generated and analysed, including a clear description of the participant's characteristics, would be helpful for other researchers to assess the transferability of the findings. Quotations from the transcribed text were provided in the report to show a connection between the data and the results, as a means to ensure confirmability. For dependability, the researchers are experienced and have extensive skills and experience in qualitative research methodology.

Despite these strengths, the following limitations were observed: the study was confined to adolescents presenting to health facilities, therefore those who missed their ANCs were not included. These were likely to be the most affected people in so far as accessibility and utilization of $\mathrm{MCHI}$ is concerned; the study focused on the age group 15 to19 and the perspectives of other young women are missing; finally, the translation of the study from Oshiwambo to English risked the loss or distortion of some meanings during the interpretation process.

\section{Conclusion}

Long travel hours to reach the nearest clinics, in terms of road infrastructure, non-availability of transport and transport fare were the overachieving findings of this study, which constituted key barriers to accessibility and utilization of clinic services. For the pregnant adolescent girls to be supported with transport fare, they needed sound justification, which inadvertently pushed them towards an early unprepared pregnancy disclosure, which was often met with harsh treatment by parents, thereby further limiting access to maternal and child services. Even after surmounting these hurdles, long queues at the clinic and the cheekiness of staff and other peers deterred them from finalizing the antenatal care, often resulting in these adolescents giving up the process. Therefore, we recommend a holistic approach inclusive of the community leaders, parents, adolescents themselves and other stakeholders. Most importantly, adolescent girls need to be empowered with information on reproductive health matters.

\section{Declarations}

\section{Ethics approval and consent to participate}

All methods were performed in accordance with the relevant guidelines and regulations. We commenced the data collection process after obtaining the full ethical clearance from the University of KwaZulu-Natal's Biomedical Research Ethics Committee (BREC), number BE512/18) and the Ministry of Health and Social Services Research Ethics Committee (MoHSSREC) and site clearance from all recruitment sites. In the beginning, the whole interview process was explained to potential participants to put them at ease and ensure that informed consent forms were signed prior to conducting the interview.

\section{Consent for publication}

Not applicable.

\section{Availability of data materials}

All data generated or analysed during this study are available from the corresponding author on reasonable request.

\section{Competing interests}

The authors declare that they have no competing interests

\section{Funding}

Not applicable

\section{Authors' contributions}

JTS designed the study, developed the tools, and undertook data collection and data analysis, and wrote the manuscript. TPM and KH participated in the design of the study and critically reviewed all the versions of the manuscript. All authors approved the final manuscript.

\section{Acknowledgments}


The authors would like to thank the Ministry of Health and Social Services in Namibia for ethical approval. Thanks also go to the managers and supervisors of the health facilities in the Ohangwena Region. Lastly, we would like to thank all the participants who willingly agreed to be interviewed.

\section{Authors Information}

1. Joyce Twahafifwa Shatilwe

Cell phone number: +264811437772

Discipline of Public Health Medicine, School of Nursing and Public Health, University of KwaZulu-Natal, Durban, South Africa.

Email address: jshatilwe@hotmail.com

2. Dr. Khumbulani Hlongwana

Discipline of Public Health Medicine, School of Nursing and Public Health, University of KwaZulu-Natal, Durban, South Africa.

Email address: Hlongwanak@ukzn.ac.za

3.Tivani Mashamba-Thompson

Research, School of Nursing and Public Health, Discipline of Public Health Medicine

University of KwaZulu-Natal, Durban, South Africa.

Department of Public Health, University of Limpopo, Polokwane, Limpopo Province, South Africa.

Email address: Mashamba-Thompson@ukzn.ac.za

\section{References}

1. WHO and UNICEF. Trends in Maternal mortality: 1990 to 2013: Estimates by WHO, UNICEF, UNFPA, The World Bank and the United Nations Pupulation Division. 2014.

2. Tsala Dimbuene Z, Amo-Adjei J, Amugsi D, Mumah J, Izugbara C, Beguy D. Women's Education and Utilization of Maternal Health Services in Africa: A Multi-Country and Socioeconomic Status Analysis. Journal of Biosocial Science. 2017 11/06;50:1-24.

3. Silumbwe A, Nkole T, Munakampe MN, Milford C, Cordero JP, Kriel Y, et al. Community and Health Systems Barriers and Enablers to Family Planning and Contraceptive Services Provision and Use in Kabwe District, Zambia. BMC health services research. 2018 May 31;18(1):390. PubMed PMID: 29855292.

4. Mbalinda SN, Nakimuli A, Kakaire O, Osinde MO, Kakande N, Kaye DK. Does Knowledge of Danger Signs of Pregnancy Predict Birth Preparedness? A Critique of the Evidence from Women Admitted with Pregnancy Complications. Health Res Policy Syst. 2014;12.https://doi.org/10.1186/1478-4505-12-60

5. Ministry of Health and Social Services. Joint Review of Maternal, Newborn, Child and Adolescent Health and Nutrition Programmes in Namibia. 2016.

6. Namibia National Planning Commission. Towards Maximising the Demographic Dividend in Namibia. Demographic Dividend Study Report. 2018.

7. WHO, UNICEF, UNFPA, WBG. Trends in Maternal Mortality: 1990 to 2015. 2015.

8. Miltenburg AS, Roggeveen Y, van Roosmalen J, Smith HJ. Interventions to Promote Birth Preparedness and Complication Readiness: Factors Influencing Implementation. BMC Pregnancy Childbirth 2017.http://dx.doi.org/10.1186/s12884-017-1448-8.

9. Yasuoka J, Nanishi K, Kikuchi K, Suzuki S, Ly P, Thavrin B, et al. Barriers for Pregnant Women Living in Rural, Agricultural Villages to Accessing Antenatal Care in Cambodia: A Community-Based Cross-Sectional Study Combined with a Geographic Information System. PLOS One. 2018;13(3):e0194103. PubMed PMID: 29554118.

10. Zere E, Tumusiime P, Walker O, Kirigia J, Mwikisa C, Mbeeli T. Inequities in Utilization of Maternal Health Interventions in Namibia: Implications for Progress towards MDG 5 Targets. International Journal for Equity in Health. 2010 06/12;9:16. 
11. Ganle JK. Ethnic Disparities in Utilization of Maternal Healthcare Services in Ghana: Evidence from the 2007 Ghana Maternal Health Survey. Ethnicity \& Health. 2016;21(1):85-101.

12. Ganle JK, Parker M, Fitzpatrick R, Otupiri E. A Qualitative Study of Health System Barriers to Accessibility and Utilization of Maternal and Newborn Healthcare Services in Ghana after User-Fee Abolition. BMC Pregnancy Childbirth.

2014;14.https://doi.org/10.1186/s12884-014-0425-8

13. Ganle JK, Krampah E. Mistreatment of Women in Health Facilities by Midwives during Childbirth in Ghana: Prevalence and Associated Factors. Selected Topics in Midwifery Care: IntechOpen; 2018.

14. Cheptum J, Gitonga M, Mutua E, Mukui S, Ndambuki J, Joima W. Barriers to Access and Utilization of Maternal and Infant Health Services in Migori, Kenya. IISTE. 2014;Vol.4, No.15.

15. Goudar SS, Goco N, Somannavar MS, Vernekar SS, Mallapur AA, Moore JL, et al. Institutional Deliveries and Perinatal and Neonatal Mortality in Southern and Central India. Reprod Health. 2015;12 Suppl 2:S13.

16. Vidler M, Ramadurg U, Charantimath U, Katageri G, Karadiguddi C, Sawchuck D, et al. Utilization of Maternal Healthcare Services and their Determinants in Karnataka State, India. Reproductive Health. 2016;13:55-65.

17. Weng Y-H, Yang C-Y, Chiu Y-W. Risk Assessment of Adverse Birth Outcomes in Relation to Maternal Age. PLOS ONE. 2014;9(12):e114843.https://doi.org/10.1371/journal.pone.0114843

18. Ganchimeg T, Mori R, Ota E, Koyanagi A, Gilmour S, Shibuya K, et al. Maternal and Perinatal Outcomes among Nulliparous Adolescents in Low-and Middle-Income Countries: A Multi-Country Study. BJOG: An International Journal of Obstetrics \& Gynaecology. 2013;120(13):1622-30.

19. Mayor S. Pregnancy and Childbirth are Leading Causes of Death In Teenage Girls in Developing Countries. British Medical Journal Publishing Group; 2004.

20. Abdullah Kamal SSL. Research Paradigm and the Philosophical Foundations of a Qualitative Study. 2019 01/31;4:1386-94.

21. Kivunja C, Kuyini AB. Understanding and Applying Research Paradigms in Educational Contexts. International Journal of Higher Education. 2017 09/05;6:26.

22. Namibia National Statistical Agency. 2017.

23. NPC. Poverty and Deprivation in Namibia. Windhoek: National Planning Commission. 2015.

24. Ministry of Finance NPC. Poverty and Deprivation in Namibia. Windhoek. 2015.

25. UN. Sustainable Development Goals. 2017.

26. Wahed T, Alam A, Sultana S, Rahman M, Alam N, Martens M, et al. Barriers to Sexual and Reproductive Healthcare Services as Experienced by Female Sex Workers and Service Providers in Dhaka City, Bangladesh. PLOS One. 2017;12(7):1-19.

27. Shah R, Rehfuess EA, Paudel D, Maskey MK, Delius M. Barriers and Facilitators to Institutional Delivery in Rural Areas of Chitwan District, Nepal: A Qualitative Study. Upsala Journal Of Medical Sciences. 2018 Jun 20;15(1):110.

28. Senkoro KP, Mboera LEG, Shayo EH, Makundi EA, Olsen $\emptyset \mathrm{E}$, Momburi R, et al. Access and Utilization of Healthcare Services in Rural Tanzania: A Comparison of Public and Non-Public Facilities Using Quality, Equity, And Trust Dimensions. Global Public Health. 2016;11(4):407-22.

29. Yaya S, Uthman OA, Amouzou A, Ekholuenetale M, Bishwajit G. Inequalities in Maternal Healthcare Utilization in Benin: A Population Based Cross-Sectional Study. BMC Pregnancy Childbirth. 2018 May 31;18(1):194. PubMed PMID: 29855277.

30. Sahoo M, Som M, Pradhan J. Perceived Barriers in Accessing the Reproductive Health Care Services in Odisha. Indian Journal of Community Health. 2017;29(3):229-38.

31. Tsawe M, Susuman AS. Determinants of Access to and Use of Maternal Healthcare Services in The Eastern Cape, South Africa: A Quantitative and Qualitative Investigation. BMC Research Notes. 2014;7(1):723-32.

32. Sychareun V, Vongxay V, Houaboun S, Thammavongsa V, Phummavongsa P, Chaleunvong K, et al. Determinants of Adolescent Pregnancy and Access to Reproductive and Sexual Health Services for Married and Unmarried Adolescents in Rural Lao PDR: A Qualitative Study. Journal Of Medical Internet Research. 2018 Jun 8;18(1):219.

33. Mekonnen T, Dune T, Perz J. Maternal Health Service Utilization of Adolescent Women in Sub-Saharan Africa: A Systematic Scoping Review. BMC Pregnancy and Childbirth. 2019 2019/10/21;19(1):366.https://doi.org/10.1186/s12884-019-2501-6

34. Bwalya BC, Sitali D, Baboo KS, Zulu JM. Experiences of Antenatal Care among Pregnant Adolescents at Kanyama and Matero Clinics in Lusaka District, Zambia. Reproductive Health. 2018;15(1):124-.

Page $12 / 13$ 
35. Dzotsi HT, Oppong Asante K, Osafo J. Challenges Associated with Teenage Motherhood in Ghana: A Qualitative Study. Vulnerable Children and Youth Studies. 2020 2020/01/02;15(1):85-96.https://doi.org/10.1080/17450128.2020.1719251

36. Pandey PL, Seale H, Razee H. Exploring the Factors Impacting on Access and Acceptance of Sexual and Reproductive Health Services Provided by Adolescent-Friendly Health Services in Nepal. PLOS One. 2019;14(8):e0220855-e.

37. Montgomery-Andersen R. Adolescent Mothers: A Challenge for First Nations. International Journal of Circumpolar Health. 2004;63:274-9.

38. Domenico DM, Jones KH. Adolescent Pregnancy in America: Causes and Responses.

39. Shaikh BT, Noorani Q, Abbas S. Community Based Saving Groups: An Innovative Approach to Overcome the Financial and Social Barriers in Health Care Seeking by the Women in the Rural Remote Communities of Pakistan. Archives of Public Health $=$ Archives Belges de Sante Publique. 2017;75:57.

40. Yakubu I, Salisu WJ. Determinants if Adolescent Pregnancy in Sub-Saharan Africa: A Systematic Review. Reprod Health. 2018 Jan 27;15(1):15.

41. Lys C, Gesink D, Strike C, Larkin J. Social Ecological Factors of Sexual Subjectivity and Contraceptive Use and Access Among Young Women in the Northwest Territories, Canada. The Journal of Sex Research.2019/10/13;56(8):999 1008. 